ing the two brass plates which project beyond the edges and slide in grooves in the uprights, shown in A, thus holding it in position and at the same time admitting of a free and easy movement. A scale, not shown in the figure, on each upright, enables the student to readily bring the bar into a horizontal position.

The piece is simple, inexpensive, and gives good results.

\title{
TO DETERMINE THE HORSEPOWER OF A SMALL STEAM ENGINE.
}

\author{
By C. H. Perrine, \\ Wendell Phillips High School, Chicago.
}

One of the most popular experiments in the physics work in this school is the determination of the horsepower of a toy steam engine. A brief bulletin is prepared for the students which embraces the following outline:

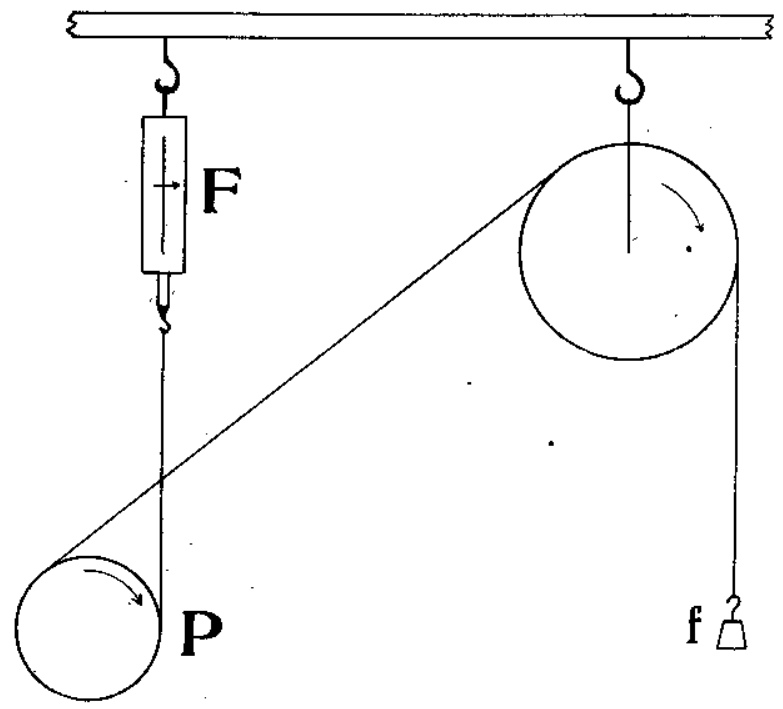

Method:- Set up apparatus as indicated in drawing. Measure the circumference of $P$ (engine pulley). This can be done sufficinetly accurately by use of string, getting the length of one turn or loop. Put a small weight at $f$ to hold the string taut. Having supplied the boiler with plenty of water, place the Bunsen flame in proper place and start the engine. Vary the load at $f$ until the speed is sufficiently slow to count accurately. The actual friction 
load which the engine is pulling, is the difference between that registered by the spring balance $F$ and the weight $f$, which is used to vary the friction.

Data required: Circumference of pulley $P$ in feet. reading of $F$ in pounds, weight of small $f$ in pounds and revolutions per minute, then

$$
\text { Horse Power }=\frac{(F-f) \times(C \times R . P . M)}{3300}
$$

Repeat the test when the engine is loaded to its maximum. Increase the load as before by varying $f$.

The results are very satisfactory. The same process is used in determining the horsepower of an electric motor or a water motor.

\section{HOME-MADE LINEAR EXPANSION APPARATUS.}

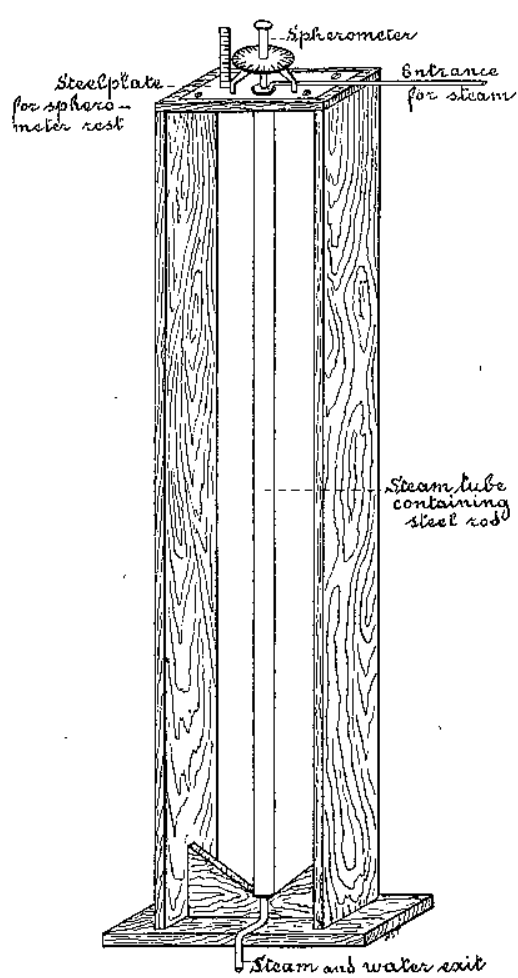

By R. O. Austin.

Central High School, Columbus, Ohio.

Exclusive of the spherometer the cost is almost nothing. Any piece of flat metal about $2 \mathrm{~mm}$. thick will answer on which to place the spherometer.

To save the trouble of putting in side tubes, two-hole rubber stoppers are t1sed, one hole for the rod and one for the steam. The apparatus may be made of any convenient length. The steam jacket is about 25 $\mathrm{mm}$. in diameter. It is not necessary to use a thermometer to determine the temperature of the steam as this can be compitted from the barometer reading. 